\title{
CONDUTÂNCIA MOLECULAR E BIOMOLECULAR
}

A. Arnóbio S. da Gama

Departamento de Química Fundamental - Universidade Federal de Pernambuco - 50670-901 - Recife - PE

Recebido em 28/1/99; aceito em 20/7/99

\begin{abstract}
MOLECULAR AND BIOMOLECULAR CONDUCTANCE. The concept of molecular conductance is discussed in terms of the propagation of an electronic interaction, between electron donor and acceptor groups, through the bonds of a molecular structure where these groups are embedded. The electronic interaction propagation is described by a Green's function matrix element, in a donor-bridge-acceptor molecular system reduced to a two-level representation.
\end{abstract}

Keywords: molecular conductance; biomolecular conductance; electron-transfer.

\section{INTRODUÇÃO}

Existe um interesse crescente por problemas relacionados com transferência de elétrons ao nível molecular, seja pela motivação biológica (fotossíntese, fosforização oxidativa) ou tecnológica (nanotecnologia). Admite-se uma base teórica unificada para todos os processos de transporte de carga em meios condensados ${ }^{1}$. Em um sistema molecular muito grande, como nos de interesse biológico, o doador e o receptor de elétrons estão fracamente acoplados e uma interação efetiva se propaga através das ligações. No limite em que esta interação é fraca, os estados doador e receptor são bem localizados, e a probabilidade de transição por unidade de tempo é proporcional ao módulo quadrado do elemento de matriz desta interação $\left(V_{d a}\right)$ e ao fator de Franck-Condon (F.C.), que leva em consideração o acoplamento entre os movimentos eletrônico e nuclear. Este é o chamado limite diabático da teoria. No limite adiabático, enfatizado na teoria original de Marcus, o acoplamento eletrônico é bastante grande e a transferência de elétrons é controlada pelo movimento nuclear (aproximação dos reagentes, reorganização do solvente e das ligações). Embora o interesse pela dinâmica do processo sugira atenção para o fator de Franck-Condon ${ }^{2}$, nos últimos quinze anos o maior esforço tem sido dedicado ao cálculo do acoplamento eletrônico.

$\mathrm{O}$ formalismo de funções de Green tem sido considerado como uma ferramenta poderosa para descrever a propagação de uma interação doador-receptor através de uma estrutura molecular muito grande, como nos sistemas de interesse biológi$\mathrm{co}^{3}$, particularmente considerando sua capacidade de fornecer expressões analíticas que generalizam ${ }^{4}$ resultados antes obtidos para sistemas unidimensionais e periódicos 5 , e sua relação formal com o particionamento de Löwdin ${ }^{6}$, ou outras técnicas de redução de matrizes ${ }^{7}$.

\section{CÁLCULO DO ELEMENTO DE MATRIZ DE INTE- RAÇÃO ELETRÔNICA PELO MÉTODO DE FUNÇÕES DE GREEN COM RENORMALIZAÇÃOO DE ORBITAIS}

Embora se tenha estabelecido uma certa polêmica a respeito das vantagens relativas entre o método de funções de Green e as técnicas de redução de matrizes ${ }^{8}$, é importante ressaltar o valor conceitual das interpretações obtidas a partir da renormalização das equações de Dyson para a função de Green ${ }^{9}$. No nosso caso, a renormalização consiste na dizimação de orbitais ${ }^{10}$, com a definição de autoenergias e interações efetivas para os orbitais remanescentes. Particularmente interessante é a aplicação deste conceito a um sistema constituído por um grupo doador de elétrons (D) e um grupo receptor de elétrons (A) ligados a uma estrutura molecular que se costuma chamar de ponte (B) ou fio molecular, como as cadeias polipeptídicas em proteínas ${ }^{11}$. A renormalização orbital sugere a redução de qualquer estrutura molecular do tipo doador-ponte-receptor a uma representação de dois estados, inclusive ao nível de um cálculo Hartree-Fock, sem restrições ao alcance das interações orbitais ${ }^{12}$.

Beratan e Onuchic têm explorado as potencialidades deste método $^{13}$, na redução de proteínas a uma representação reduzida (ou renormalizada) ${ }^{14}$, associado ao modelo de caminhos de tunelamento eletrônico ${ }^{15}$, aplicado com sucesso na reprodução e previsão de velocidades de transferência de elétrons em metaloproteínas modificadas com rutênio pentaamina ${ }^{16}$. Nos sistemas biológicos, os caminhos são determinados pelo enovelamento das cadeias polipeptídicas, com participação decisiva das ligações por pontes de hidrogênio e outras interações intermoleculares.

Mujica e colaboradores ${ }^{17}$ têm abordado a relação bastante nítida entre transferência de elétrons diabática, em sistemas doador-ponte-receptor, e microscopia de tunelamento de varredura, em que são feitas medidas baseadas no transporte de elétrons, através de um material de interesse colocado entre eletrodos. Nestas condições, estes autores definem a condutância da ponte, como um fio molecular, em termos de um elemento de matriz da função de Green:

$\sigma=\frac{2 \pi \varepsilon^{2}}{\mathrm{~h}}\left|G_{I N}(E)\right|^{2} V_{D}(E) V_{A}(E) \rho_{D}(E) \rho_{A}(E)$

onde o parâmetro $V_{D}(E) / V_{A}(E)$ corresponde à interação do doador/receptor com a ponte e o elemento de matriz da função de Green, $G_{1 n}(E)$, descreve a propagação de uma interação através da ponte, desde onde se liga ao doador (1) até onde se liga ao receptor $(N)$, na energia em que o elétron é transferido (energia de tunelamento eletrônico). Neste modelo, a densidade de estados, contida no fator de Franck-Condon, apresenta-se particionada entre o doador $\left(\rho_{D}(E)\right)$ e o receptor $\left(\rho_{A}(E)\right)$. É interessante observar o comportamento de $G_{I N}(E)$ para diferentes pontes, embora a condutância de um fio molecular dependa explicitamente do acoplamento com doador e receptor.

Existe uma variedade de parâmetros para controlar a condutância de um fio molecular. O mais importante, do ponto de vista puramente eletrônico, é a sequência de elementos e suas ligações. A dependência da condutância com as interações entre as unidades constituintes da ponte depende de diversos fatores, a natureza e orientação de grupos ou cadeias laterais, ou simplesmente pares de elétrons isolados ${ }^{18}$. Também importante é a correlação entre estes efeitos, como, por exemplo, entre grupos laterais e orientação. 
A procura de caminhos de propagação para a interação eletrônica entre doador e receptor, através da ponte molecular, é uma estratégia extremamente útil para que se possa prever como os detalhes da estrutura molecular controlam a condutância da ponte.

\section{PROPAGAÇÃO DA INTERAÇÃO ELETRÔNICA ATRAVÉS DE PONTES UTILIZADAS EM SISTEMAS MODELO}

Diversos sistemas modelo tem sido sintetizados e utilizados em experimentos de transferência de elétrons. Alguns destes sistemas consistem de porfirinas ligadas a outras porfirinas ou quinonas, que são os constituintes dos sistemas fotossintéticos naturais, através de pontes formadas por uma sequência de grupos saturados, insaturados ou mistos. Dímeros de porfirinas com pontes contendo de um a três grupos benzeno tem sido estudados por McLendon ${ }^{19}$. Sistemas semelhantes em que o grupo benzeno central é substituído por um grupo saturado, como cicloexano ou piprazina, foram estudados por Portela e colaboradores ${ }^{20}$.

Cálculos teóricos para o fator eletrônico nessas pontes foram realizados utilizando métodos de química quântica ab initio e semiempírico ${ }^{21}$. Cálculos pelo método de funções de Green estão sendo feitos também ao nível Hartree-Fock, ab initio e semiempírico $^{22}$. Utilizando um modelo mais simplificado, com interações restritas aos primeiros vizinhos, observa-se um comportamento qualitativo consistente com os cálculos mais rigo$\operatorname{rosos}^{18}$. Nestes cálculos simplificados foram utilizados parâmetros de energia orbital e interações entre orbitais obtidos da matriz de Fock dos cálculos quânticos realizados com geometria previamente otimizada. Um aspecto particularmente interessante dos resultados é a análise que se pode fazer sobre a capacidade de previsão de cálculos bastante simplificados, como aqueles utilizados com o modelo de caminhos de tunelamento eletrônico em sistemas biológicos ${ }^{16}$.

Como um teste, apresentamos uma discussão sobre as diferenças nas condutâncias das pontes mostradas na Figura 1, com base no modelo mais simples possível, que considera apenas as ligações e as interações entre ligações. Nesta discussão, além do mais, consideramos apenas as ligações $\sigma$. Os cálculos mais rigorosos concordam com a pouca ou nenhuma influência das ligações $\pi$ na propagação da interação eletrônica através destas pontes nas conformações mais estáveis ${ }^{18,21,22}$.

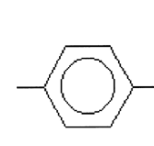

(I)

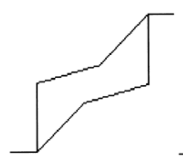

(II)

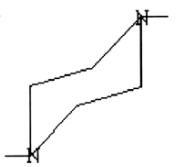

(III)

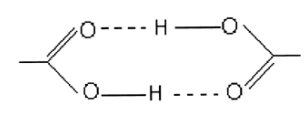

(IV)
Figura 1. Estruturas moleculares utilizadas como unidades constituintes de pontes em sistemas modelo: insaturada (I), saturada (II), saturada com pares isolados (III) e com ponte de hidrogênio (IV).

O modelo simplificado assume que cada ligação tem uma energia $\alpha$ e a interação entre ligações é simbolizada por $\beta$. Os pares isolados apresentam uma energia diferenciada, $\alpha_{\mathrm{p}}$, menos negativa, por não participarem de ligações. Adotamos então uma estratégia de renormalização obtital, na qual são eliminadas ligações sucessivamente e redefinidas, em cada etapa, as energias das ligações que interagem com a ligação eliminada e as interações efetivas entre ligações que interagem com a ligação eliminada ${ }^{23}$. Assim, as correções de interação entre duas ligações, quando se elimina uma ligação lateral $\mathrm{CH}\left(\beta_{i}^{e f}\right)$, duas ligações laterais $\mathrm{CH}\left(\beta_{s}^{e f}\right)$ ou um par isolado $\left(\beta_{p}^{e f}\right)$, apresentam-se, respectivamente, como:

$\beta_{i}^{e f}=\beta+\frac{\beta^{2}}{E-\alpha} \beta_{s}^{e f}=\beta+\frac{2 \beta^{2}}{E-\alpha-\beta} e \beta_{p}^{e f}=\beta+\frac{\beta^{2}}{E-\alpha_{p}}$
Para descrever o efeito de ligações laterais ou pares isolados, sobre a condutância de um fio molecular, pode-se considerar uma simples sequência linear de ligações equivalentes, em que:

$G_{I N}(E)=\frac{1}{E-\alpha}\left(\frac{\beta}{E-\alpha}\right)^{n-1}$

onde $n$ é o número de unidades entre o doador e o receptor. Pode-se, então, definir o parâmetro $\varepsilon(E)=\frac{\beta}{E-\alpha}$ para descrever o que acontece com a propagação da interação ao passar de uma ligação para outra com energia $\alpha$, com uma interação $\beta$ entre elas, na energia em que o elétron está sendo transferido $(E)$.

Para efeito de ilustração, considere-se a passagem entre a primeira e a segunda ligação em cada uma das unidades que constituem as pontes da Figura 1, insaturada (i), saturada (s) e com par isolado (p), tem-se:

$\varepsilon_{i}(E)=\frac{\beta}{E-\alpha-\frac{\beta^{2}}{E-\alpha}}$

$$
\varepsilon_{s}(E)=\frac{\beta+\frac{\beta^{2}}{E-\alpha}}{E-\alpha-\frac{2 \beta^{2}}{E-\alpha}-\frac{\beta^{2}}{E-\alpha}}
$$

$$
\varepsilon_{p}(E)=\frac{\beta+\frac{\beta^{2}}{E-\alpha_{p}}}{E-\alpha-\frac{2 \beta^{2}}{E-\alpha}-\frac{\beta^{2}}{E-\alpha_{p}}}
$$

Considerando que a condução se processa através dos estados ocupados, a energia de tunelamento está acima da energia dos estados da ponte e os termos de correção apresentam sinal contrário às interações diretas, caracterizando a interferência destrutiva. Assim, fica evidente, que para o grupo com ligações saturadas, a interferência é maior que para o grupo com ligações insaturadas. No caso do par isolado, pode-se notar, que sendo sua energia mais alta, portanto mais próxima da energia de tunelamento, o denominador é menor e a interferência destrutiva maior. A Figura 2 mostra o comportamento destes parâmetros em um intervalo de energia adequado para descrever estados localizados e condução por buracos, isto é: a energia do elétron sendo transferido está acima dos estados ligados e suficientemente distante para que se possa caracterizar estados localizados no doador e no receptor. Nestas condições o elemento de matriz da função de Green varia suavemente com a energia ${ }^{24}$. Na Figura 3 é apresentado o comportamento do elemento de matriz da função de Green entre as ligações extremas $\left(G_{15}(E)\right)$ para cada uma das unidades consideradas.

Este modelo simples, além de apresentar resultados que concordam qualitativamente com os resultados mais rigorosos, permite uma interessante interpretação sobre os fatores eletrônicos que controlam a condutância das pontes. A ponte com grupos aromáticos deve ser mais eficiente, não por causa das ligações $\pi$, mas por apresentar um menor número de ligações laterais. Com um cicloexano no lugar do anel aromático, introduz-se mais ligações laterais $(\mathrm{CH})$ em cada carbono e assim mais interferência destrutiva no caminho de tunelamento eletrônico. $\mathrm{O}$ modelo mostra este resultado analiticamente, e sugere que, se lateral- 


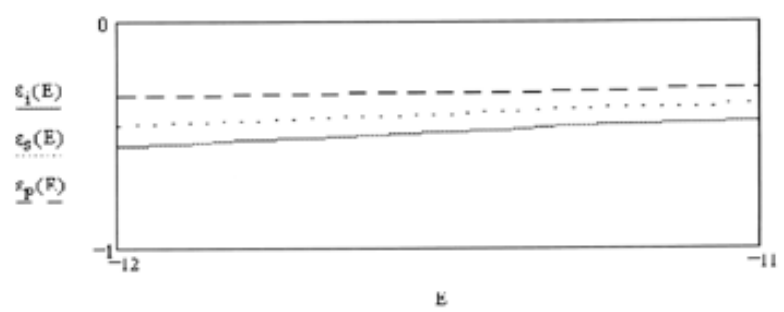

Figura 2. Comportamento de $\varepsilon(E)$ em função de E, em uma estrutura insaturada $\left(\varepsilon_{i}(E)\right)$, linha contínua, saturada $\left(\varepsilon_{s}(E)\right)$, linha pontilhada, e saturada com par isolado $\left(\varepsilon_{p}(E)\right)$, linha tracejada.

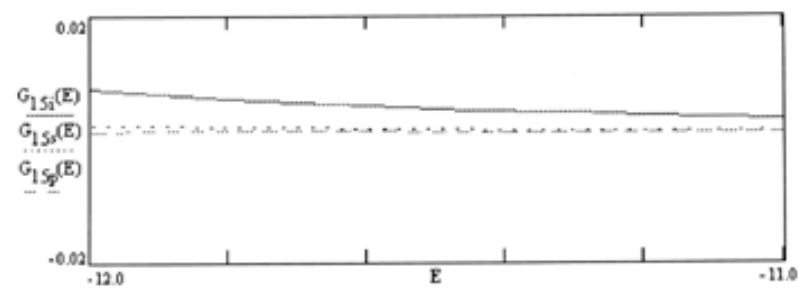

Figura 3. Comportamento de $G_{I N}(E), N=5$, em função de E, através de cada uma das unidades, insaturada $G_{15 i}(E)$, linha contínua, saturada $G_{I N s}(E)$, linha pontilhada, e saturada com par isolado $G_{I N p}(E)$, linha tracejada.

mente estiver uma ligação ou grupo com energia mais alta, a interferência destrutiva deverá ser mais acentuada. Este será o caso se o grupo utilizado for uma piperazina, com o mesmo número de ligações laterais $\mathrm{CH}$ nos carbonos centrais e pares isolados no lugar de ligações $\mathrm{CH}$ nos carbonos das extremidades. O modelo simplificado prevê, e os cálculos mais rigorosos confirmam $^{18,21,22}$, que a ponte com piperazina deverá ser a menos eficiente.

Considerando que os caminhos de tunelamento em proteínas são particularmente influenciados pelas interações via ponte de hidrogênio, sistemas modelo como o mostrado na Figura 1 (IV), contendo um dímero de ácido carboxílico no caminho de tunelamento $^{25}$, têm despertado grande interesse. Como esperado, o elemento de matriz da função de Green, e portanto o acoplamento eletrônico, indica que esta ponte tem condutância ainda menor que as discutida anteriormente ${ }^{18}$. Mas, é interessante considerar, que além do caminho passar obrigatoriamente pelas pontes de hidrogênio, que implicam em uma interação mais fraca que uma ligação covalente, há dois pares de elétrons isolados em cada oxigênio. Pontes desta natureza precisam ser estudadas com maior atenção para distinguir as contribuições da ponte de hidrogênio e da interferência via pares isolados no decréscimo da condutância prevista.

\section{SISTEMAS BIOLÓGICOS}

Nas proteínas as estruturas secundária e ternária exercem importante papel no transporte de elétrons. Se um sítio se encontra acomodado em um trecho da proteína em folha $\beta$, altamente conectada, seu acoplamento com outro sítio, também acomodado em trechos em folha $\beta$, será muito mais eficiente do que quando entre os sítios há um trecho de proteína em hélice $\alpha^{26}$.

Mesmo em uma simples cadeia peptídica, pode-se observar que um contato via ponte de hidrogênio, entre um grupo $\mathrm{NH}$ e um grupo $\mathrm{CO}$, quatro unidades peptídicas adiante, é mais eficiente na propagação do acoplamento, que a sequência de ligações covalentes entre esses grupos. Pode-se comprovar esse comportamento na Figura 4, em que se apresenta um gráfico do elemento de matriz da função de Green, $G_{1 N}(E)$, e as duas parcelas que o compõem, uma através das ligações covalentes da cadeia, $G_{I N c}(E)$, e outra via ponte de hidrogênio, $G_{1 N h}(E)$.
Pode-se observar que a contribuição via ponte de hidrogênio praticamente determina a propagação da interação eletrônica, exceto quando a energia em que o elétron é transportado se aproxima dos estados da ponte, e o modelo teórico utilizado se torna inadequado.

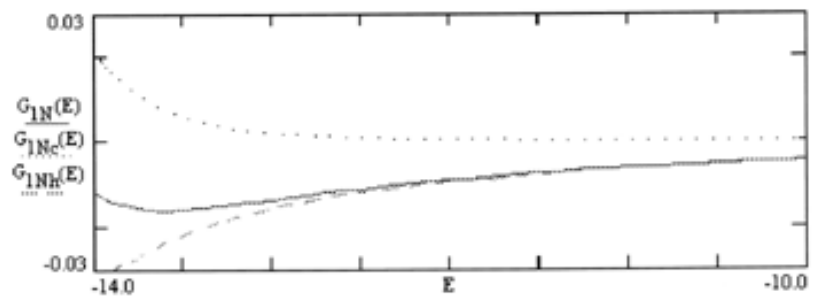

Figura 4. Comportamento de $\mathrm{G}_{1 \mathrm{~N}}(\mathrm{E})$, em função de $\mathrm{E}$, através de um trecho de cadeia polipeptídica entre um grupo $\mathrm{NH}$ e um grupo $\mathrm{CO}$, que interagem via ponte de hidrogênio. $\mathrm{G}_{1 \mathrm{Nc}}(\mathrm{E})$, em linha pontilhada, é a contribuição através das ligações covalentes da cadeia e $\mathrm{G}_{1 \mathrm{Nh}}(\mathrm{E})$, em linha tracejada do caminho via ponte de hidrogênio. $\mathrm{G}_{1 \mathrm{~N}}(\mathrm{E})$, em linha contínua, representa a soma das duas contribuições.

Estudos da importância de caminhos em sistemas biológicos confirmam que as interações via ponte de hidrogênio são predominantes na determinação da propagação eletrônica ${ }^{27}$.

\section{CONCLUSÃO}

A condutância do meio que desempenha o papel de intermediário no transporte de elétrons em sistemas biológicos ou modelos sintéticos depende de detalhes da estrutura eletrônica, entre os quais devem ser considerados grupos e/ou ligações laterais, pares isolados e particularmente contatos não covalentes, como as pontes de hidrogênio, que proporcionam caminhos alternativos a uma longa sequência de ligações covalentes.

$\mathrm{O}$ método de funções de Green proporciona ferramentas poderosas para descrição qualitativa dos efeitos destes detalhes estruturais sobre a condutividade de diferentes pontes (fios moleculares) ou caminhos que utilizam contatos não covalentes. Particularmente, a aplicação do método sobre um modelo simplificado da estrutura molecular, que considera interações apenas de primeiros vizinhos, permite visualizar como se pode modificar a estrutura para aumentar a eficiência na propagação da interação eletrônica entre doador e receptor. Embora a condutância do fio molecular, ou caminho de tunelamento eletrônico, dependa explicitamente dos doadores receptores, o elemento de matriz da função de Green depende apenas da estrutura da ponte. A dependência deste elemento de matriz com doadores e receptores aparece apenas na energia de tunelamento, isto é: na energia em que o elétron está sendo transferido.

Os exemplos tratados sugerem que a presença de menos ligações laterais torna a condutância de cadeias insaturadas maior que de cadeias saturadas, embora não se esteja considerando a contribuição das ligações $\pi$. Estes resultados são confirmados por cálculos mais rigorosos. Também se observa que a presença de par isolado, ao invés de ligação lateral, contribui para redução da condutância de um fio molecular.

\section{REFERÊNCIAS}

1. a) Jortner, J.; Biochim. Biophys. Acta 1980, 594, 193 ; b) Marcus, R. A.; Sutin, N.; Biochim. Biophys. Acta 1985, $811,265$.

2. Skourtis, S. S.; Beratan, D. N.; J. Phys. Chem. B 1997, 101, 1215.

3. da Gama, A. A. S.; Theor. Chim. Acta 1985, 68, 159.

4. da Gama, A. A. S.; Quím. Nova 1988, 11, 76. 
5. McConnell, H. M.; J. Chem. Phys. 1961, 35, 508; b) Davydov, A. S.; Phys. Stat. Solid B 1978, 90, 457; c) Petrov, E. G.; Int. J. Quant. Chem. 1979, 16, 133.

6. Larsson, S.; J. Am. Chem. Soc. 1981, 103, 4034.

7. Day, R. S.; Suhai, S.; Ladik; J., Chem. Phys. 1981, 62, 165.

8. Everson, J. W.; Karplus, M.; J. Chem. Phys. 1992, 96, 5272 .

9. dos Santos, M. C.; de Melo, C. P.; Brandi, H. S.; Int. J. Quant. Chem. 1986, 30, 109.

10. Levstein, P. R.; Pastawski, H. P.; D’Amato, J. L.; J. Phys. C: Condensed Matter 1990, 2, 1781.

11. da Gama, A. A. S.; J. Theor. Biol. 1990, 142, 4500.

12. a) Coutinho-Neto, M. D.; da Gama, A. A. S.; J. Mol. Struct. (THEOCHEM) 1995, 330, 437, b) Coutinho-Neto, M. D.; da Gama, A. A. S.; Chem. Phys. 1996, 203, 43.

13. a) de Andrade, P. C. P.; Beratan, D. N.; Onuchic, J. N.; J. Chem. Phys. 1991, 95, 1131; b) Curry, W. B.; Grabe, M. B.; Kurnikov, I. V.; Skourtis, S. S.; Beratan, D. N.; Regan, J. J.; Aquino, A. J.; Peroza, P.; Onuchic, J. N.; J. Bioenerg. Biomemb. 1995, 27, 285.

14. a) Skourtis, S. S.; Regan, J. J.; Onuchic, J. N.; J. Phys. Chem. 1994, 98, 3379; b) Skourtis, S. S.; Beratan, D. N.; J. Phys. Chem. B 1997, 101, 1215.

15. Beratan, D. N.; Onuchic, J. N.; Hopfield, J. J.; J. Chem. Phys. 1987, 86, 4488.
16. Beratan, D. N.; Onuchic, J. N.; Betts, J. N.; Bowler, B. E.; Gray, H. B.; J. Am. Chem. Soc. 1990, 112, 7915.

17. Mujica, V.; Kemp, M.; Ratner, M. A.; J. Chem. Phys. 1994, 101, 6849.

18. Parnaíba-daSilva, A. J.; da Gama, A. A. S.; Chem. Phys. Lett., 1998, 296, 483.

19. Helms, A.; Heiler, D.; McLendon, G.; J. Am. Chem. Soc. $1992,114,6227$.

20. Portela, C. F.; Brunckova, J; Richards, J. L. ; Schöllhorn, B.; Iamamoto, Y.; Magde, D.; Traylor, T. G.; Perrin, C. L.; J. Phys. Chem . A 1999, 103, 10540.

21. do Monte, S. A., Monografia de Graduação, UFPE, Recife, 1996.

22. de Santana, O. L.; Dissertação de Mestrado, UFPE, Recife, 1999.

23. da Gama, A. A. S.; Quím. Nova 1994, 17, 62.

24. a) Skourtis, S.; Onuchic, J. N.; Chem. Phys. Lett.; 1993, 209, 171; b) Skourtis, S.; Onuchic, J. N.; Beratan, D.; Chem. Phys. 1993, 176, 501.

25. De Regge, P. J. F.; Williams, S. A.; Therien, M. J.; Science 1985, 269, 1409.

26. Beratan, D. N.; Betts, J. N.; Onuchic, J. N; Science 1991, 252, 1285.

27. de Andrade, P. C. P.; Onuchic, J. N.; J. Chem. Phys. 1998, $108,4292$. 